\title{
Contextualising Postmodernity in Daoist Symbolism: \\ Toward a mindful education embracing eastern wisdom
}

Rob Blom \& Chunlei Lu

Originally Published in:

Routledge: Taylor and Francis Group

Educational Philosophy and Theory (EPAT)

Philosophy of Education Society of Australasia (PESA)

To cite this article: Rob Blom \& Chunlei Lu (2016): Contextualising Postmodernity in Daoist Symbolism: Toward a mindful education embracing eastern wisdom. Educational Philosophy and Theory. DOI: 10.1080/00131857.2016.1190266

To link to this article: http://dx.doi.org/I0.I080/oo131857.2016.1190266

Published online: $\quad$ I2 Jul 2016.

ORCID

Chunlei Lu

http://orcid.org/oooo-0002-8623-0274 


\begin{abstract}
In cultivating a Western inclination toward Eastern wisdom, it is important to seek the foundations that sustain traditional practices toward such end. In a secularised and modern world view, the tendency has been to extract and abstract foundational practices such as mindfulness meditation and contemplation within an objectivist or scientistic prejudice. While leading to interesting results, it cannot ascertain a wisdom that is quantified and decontextualised. In response, contextual effort in postmodern pedagogical literature-while well placed-is often marred with confusions concerning Eastern and metaphysical foundations. As a result, one is led away from the very wisdom being qualified; furthermore, conceptual and theoretical paradoxes arise and consequently elude those that formulate them. Thus, in feeling secure in response to a particular 'yáng' world view of modernity, many postmodern criticisms suffer an exclusively 'yin' character. For us, imbalance in any direction forfeits the path Eastern education approaches wisdom. In our conceptual analysis, we contextualise that modernity was never too yáng, but too yáng-in-yin. Therefore, what is missing in pedagogical theory is not the yin element, as presumed by postmodern critique, but the yáng element, in continual balance with the yin, and vice versa.
\end{abstract}

Keywords: $\quad$ mindfulness, wisdom, metaphysics, education, Daoism, hierarchy

\title{
Authors' biography
}

Rob Blom holds a Bachelor's degree in Mathematical physics from the University of Waterloo and a Master's degree in Education from Brock University, Canada. He has both teaching and administrative experience in the educational sector in Canada and China. His personal interests include permaculture, Eastern and Western meditations, and atheletics while academic interests include educational trends in complexity theory and deep ecology and post-postmodern (or pre-modern) educational trends in Eastern Mindfulness, Platonic philosophy, and perennial metaphysics. He was a student of Dr. Chunlei Lu. Email: rob.blom85@gmail.com

Chunlei Lu is currently a Full Professor in Faculty of Education, Brock University, Canada. He was also the Co-Director of Confucius Institute and the Director of Centre for Continuing Teacher Education at Brock University. He obtained a BEd (Shandong Normal University, China), MEd (Zhejiang University, China), MSc (State University of New York at Brockport, USA), and PhD (University of Alberta, Canada). He has teaching experiences in seven universities in the three countries. Further, he had school teaching certificates in both China and Canada. Based on these cross-cultural experiences, his research interests have concentrated on the overlapped areas of culture, education, and health. He has published 2 books, 7 book chapters, and over 6 o refereed articles around the world. Email: chlu@brocku.ca 


\section{Toward a Mindful Education Embracing Eastern Wisdom}

In resonance with an interconnected, holistic - and dare we say postmodern-world-view, one may ascertain that 'the farthest West is but the farthest East' (Smith, 2006); but taking a page from Rudyard Kipling, we could also say 'East is East, and West is West, and never the twain shall meet.' While any systematic or philosophical thought will have its antithesis—especially one of extremes—it may be prudent to justify the middle path, with, perhaps, a slight leaning toward one or the other depending upon one's situated hermeneutic context. For the purpose of our criticism, we wish to attenuate the former perspective which too hastily connects East and West.

In cultivating a Western inclination toward Eastern wisdom, it is important to seek the foundations that sustain traditional practices toward such end. In a secularised and modern(ised) world view, the tendency has been to extract and abstract foundational practices like mindfulness meditation and contemplation within an objectivist or scientistic prejudice (Blom, Lu, \& Mgombelo, 2015). While leading to interesting results, it cannot ascertain a wisdom that is quantified and decontextualised. In response, contextual effort in postmodern pedagogical literature-while well placed - is often marred with confusions concerning Eastern and metaphysical foundations. As a result, one is led away from the very wisdom being qualified. Furthermore, conceptual and theoretical paradoxes arise and consequently elude those that formulate them. Thus, in feeling secure in response to a particular ' yáng' (阳) world view of modernity—advocating against what is masculine, certain, mechanical, hierarchical, patriarchal, and so on- many postmodern criticisms suffer an exclusively yin (阴) character. For us, imbalance in any direction forfeits the path Eastern education approaches wisdom (sophia, zhibui, 智慧).

Utilising Daoist symbolism, we aim to encapsulate postmodernist trends, their supposed critiques against modernity, and the subtle contextualisation we 'un-Earthed' from their combination (see Figure 2). From our exploration, an immediate consequence arises: modernity was never too yáng, but too 'yáng-in-yīn;' and with our concluding conceptual map, we encourage future pedagogy theorists interested in Eastern wisdom-in a Westernised light - to recognise an integral yin-yáng balance. It is within the context of metaphysics to which Eastern mindfulness (sati, niàn, 念) and wisdom—a balance of character and discerning intelligence ( $z b i$, 智) -rightfully belong.

\section{Postmodern Criticism of Modernity as 'Too Yáng' is Really 'Too Yáng-in-Yīn'}

As a historical epoch after modernity, postmodernity denotes the state of a society or individual as being postmodern. However, postmodernity has been argued as a continuation of - and thus within - modernity, or as a cultural backlash against modernity and the state of being modern; thus, any strict definition of a 
postmodern theorist is elusive. Nonetheless, a common critique held against modernity has been its anachronistic qualities present in our world. Modes of thinking that are rational, analytic,reductionist, and linear, and value systems that are competitive, quantitative, and domineering are labelled as 'masculine' (yáng); its feminine $(y \bar{m})$ counterpart contrasts thinking as intuitive, synthetic, holistic, and nonlinear, encompassed in a values ystem of cooperation and (e)quality (Capra, 1997, p. I0). These intersubjective qualities seem equally enmeshed in an interobjective science of the biosphere-colloquially termed the 'web of life'-and the tenets of deep ecology, typified by irreducible wholes, networks, interrelationships, and interdependencies.

Prevalent across deep ecological (ecomasculinist) and ecofeminist attitudes is a re-enchantment with the feminine $(y \bar{m})$ principle; we could also say a re-enchantment with Nature, ${ }^{2}$ Earth, or our bodies (in contrast to mind). The 'disenchantment' may well have been under way since agrarian times, however, Eco-Romantic critique is often levelled toward decontextualised 'absolutes' or 'universals' inherited from the EgoEnlightenment thinkers of seventeenth-century modernity. As Toulmin (1990) ascertained, 'one aim of seventeenth-century philosophers [Descartes and contemporaries] was to frame all their questions in terms that rendered them independent of context [emphasis added]' (p. 2I); the consequence of four centuries of reductionist scientific thinking, sub specie aternitatis, ${ }^{4}$ is that certainty replaced bumanism, formal logic replaced rbetoric, and permanences replaced the transitory. For better and worse, these absolutes are in part due to the reflection paradigm with the emergence of reason as the centre of social gravity (Wilber, 200o). In the latter case, reason succumbed to rationality and confined itself to empiric-analytic, objectifying, monological, ${ }^{6}$ or positivistic modes- hence 'absolutes' were studied separate from the Cartesian notion of the 'thinking thing' (res cogitans): a mind dissociated from body. Over time, a reductionist (intersubjective) culture birthed its social (interobjective) counterpart: the mechanical and uniform(ing) era of industry. The industrial age saw the world metaphorically as a machine devoid of life and 'based on the assumption of separability and manipulability' (Shiva, 1989 , p. 22). Metaphysically, 'industry is really the opposite of "true craft" as the partisans of "progress" so readily declare, a "thing of the past". The workman in industry cannot put into his work anything of himself' (Guénon, 1946/2004, p. 60). Therefore:

The machine is in a sense the opposite of the tool, and is in no way a 'perfected tool' as many imagine, for the tool is in a sense a 'prolongation' of the man himself, whereas the machine reduces the man to being no more than its servant; and, if it was true to say that 'the tool engenders the craft' it is no less true that the machine kills it.7 (p.6o)

Historically, the appeal for mass-production - a truly quantitative notion-did not limit itself to industry, but extended to branches of both science in the form of predictive power and Westernised education in the form of schooling and discipline (Davis, 2004). ${ }^{8}$ In classroom 'mechanics,' (so-called yáng) metaphors of maximisation, efficiency, output, uniformity, certitude, and control stood deliberate as quantifiers of positivist 
(input-output) learning; the 'neglect is manifest, for example, in scientific technologies that are deployed in ignorance of their environmental consequences ... and in educational systems structured around ageappropriate (vs. situation- or person-appropriate) standardised curricula' (p. I6I). Even in pedagogical research, uniformity persists to statistically maintain quantifiers.

Within the information age is the recognition that the whole system is more than the sum of its abstracted parts; contrasted to reductionism comes 'systems thinking' or 'environmental (contextual) thinking' (Capra, 1997). Co-incidentally, Nature (physis, $\varphi v$ vis) as manifestation etymologically implies becoming and evolution, which we see ubiquitously in paradigmatic science today. For physics, a Cartesian-Newtonian legacy of timeindependent equations is replaced with time-irreversible probability densities $\rho(\mathrm{r}, \mathrm{t})$ in credit to Ilya Prigogine, whose dissipative structures and bifurcation theory, moreover, affected the domain of chemistry. In cellular

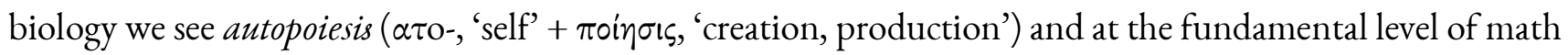
appears Tarski and Gödel's incompleteness theorems, chaos theory, complexity (nonlinear dynamics), and fractals. Each have elements of indeterminacy,unpredictability, incompleteness, or uncertainty. As Capra (1997) noted, the use of negating prefixes show how deeply ingrained Cartesian-Newtonian concepts are in our scientific mentality! Perhaps Heraclitus said it best: no person ever steps into the same river twice.

One may ponder the raison d'être for a mechanical, parts-based approach to knowledge, which undeniably underlies the compartmentalisation of education, agriculture, science, and so on. Perhaps we had to stray to recognise the inherent errors of our scientific assumptions and beliefs-making science-and the education that supports it —an evolving knowledge system. ${ }^{9}$ Could reductionist, quantitative, and uniforming tendencies have matched a consciousness that reflected the mental habits of centuries past? Habits presumably 'yáng' and 'modern' from the vantage of postmodern lenses? Today, holistic or wholistic (ecological) metaphors of optimisation, embodiment, diversity, and creativity abound. Educationally, a 'learning system' becomes an 'enactive system;' biologically, 'personal learning is not about acquisition, processing, or storing, but about emergent structuring' (p. 165). Similarly, embodiment practices that emphasise mindful participation focuses on the reconnection between mind and body (Lodewyk, Lu, \& Kentel, 2009). In summary, ecological postmodern literature advocates difference, multiplicity, diversity, and communion over agency and uniformity. These are among many trends we perceive to be beneficial arising from the reclamation of the feminine (yin) principle. However, can reclamation infer a yin tendency replaces a yáng? In Daoist theory, yin and yáng are relative, harmoniously coexisting toward development as contraries (restrictive) or from a higher perspective as complementaries (facilitative); their roles in manifestation are not fixed, and although in continual integration yin and yáng may exchange their positions, we find this unlikely and look toward the reclamation of the yáng; in absence of metaphysics, we place the inevitably paradoxes from the yin imbalance under scrutiny. 


\section{Conceptual Errors and Paradoxes of the yin Imbalance}

According to Wilber (2000), the central problem of modernity has been how human subjectivity (as will and agency) relates to the world; put differently, how do mind and body relate? The Ego-Enlightenment camp stressed autonomy against beteronomy so moral freedom could prevail over amoral nature; reason, they argued, birthed individualism and allowed the mind to transcend biospheric inclinations-a differentiation of the mind from body. It was reason (through the rational-ego) that rose to worldcentric compassion above egocentric and ethnocentric drives relating to an amoral nature (and Nature). Thus, an autonomous ego or self-defining subject coupled a cultural emergence of moral consciousness; moral life became equivalent to freedom from a mind differentiated from body (Wilber, 200o). Conversely, Eco-Romantics argued against propositional truth arising from autonomous reflection on Nature, emphasised truthfulness through embodied expression, and participatory communion over agentic isolation. Unity and wholeness were to be found in sympathy and Nature - a point the Ego camp would chastise as regressive; likewise, against the Ego camp, a subjectivity denoted in (a false) absolute language denigrates the emancipatory potential of rationality to forms of control, domination, repression (of body), and so on (Wilber, 200o).

Rationality, as it originated, meant 'the capacity for [universal] perspectivism, for sustained introspection, and for imagining "as-if" and "what-if" possibilities. Rationality [was] the sustained capacity for cognitive pluralism and perspectivism' (Wilber, 200I, p. 229). However, the universal perspectivism (yinn-yáng balance) that initiated the Ego-Enlightenment era collapsed to universal (too yáng-in-yīn): an atomistic uniformity (absolutism-in-naturalism) where homogenisation diluted world-centric perspectives to one for all cultures (what is good for me is good for everyone). Conversely, the celebration of diversity (perspectives) from the Eco-Romantics 'started from the same rational stance of universal perspectivism, but it emphasised the "perspectives" instead of the "universal”' (p. 483), becoming too yin (Figure 3). Each position became irreducible contraries - a subsequent dualism (the more of one, the less of the other) - that led to respective paradoxes and pathologies.

For the Eco camp, extreme diversity slid into divine egoism (all are unique), begetting agentic isolation; regarding bypercommunion, one loses sense of self and diverse community succumbs to uniforming worldviews. For the Ego camp, 'the holism of nature produced the atomism of the self' (Wilber, 200o, p. 44I), leaving the subject 'I' disengaged in non-participatory communion by its own self-defining agency; an agency, moreover, whose function depended upon the very communion it repressed..$^{\text {10 }}$ Moreover, to preserve its own transcended autonomy, the rational-ego not only repressed the body, but discarded further transcendence toward the psychic ( $\left.\psi v \chi \eta^{\prime}, p s u c h e ́\right)$ and subtle(r) stages of self-sense development (and thus greater autonomy); therefore, the freedom it sought became unfreedom by denying anything hierarchical beyond egoic-rationality (trans-rationalities). Educationally, we see byperagency in the goal of critical pedagogues who espouse universal 
emancipation, specifically against an anti-environmental industrial paradigm. Seeing previous generations and ideologies as oppressive, universal emancipation then implicates the anti-environmental position by assuming the 'loss of intergenerational knowledge and networks of mutual aid [are] a necessary part of becoming modern' (Bowers, 2oIo, p. 5). Therefore, 'by ignoring that the life supporting characteristics of natural systems are in decline, they can maintain the myth that each generation will become more enlightened and selfdirecting' (p. II).

To remedy these deficiencies and paradoxes requires depth (bierarchy) and the concept of a bolon ("̈ $\lambda$ ov; from the Greek neuter form bolos, 'ò $\lambda$ os, whole'). A holon is neither a whole nor a part, but simultaneously a whole/part comprising four quadrants (Figure I) and coupled with its own relative agency and communion; through greater depth, a holon transcends to meet its relative agentic and communal deficiencies, ad indéfinitum. For example, a holon at the world-centric stage for moral development will perceive and act in the world that encompasses (and transcends) an ethnocentric stage; this is true for any developmental line: cognitive, affective, self-identity, or so on. If a holon becomes too whole (hyperagency) or too much a part (hypercommunion), pathology ensues. Balance is preferably to vacillation, and stillness gives rise to transcendence.
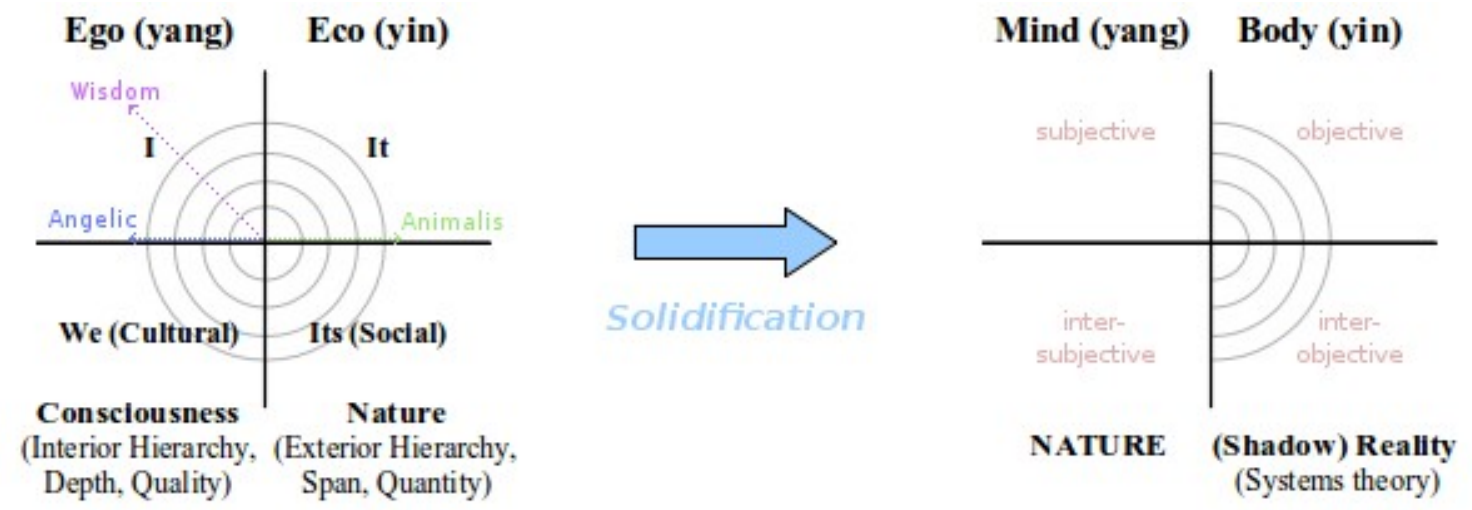

Figure I: Adaptation of Integral Model showcasing solidification toward the exclusively yin and quantitative

Notes: In a monological or flatland worldview, no interpretation and no mutual understanding exists, only 'surfaces' without any value. Hierarchy or depth (within), represented by concentric circles, becomes replaced by heterarchy and a flatland ontology (Wilber, 200o). On the right, a disengaged subject reflects on a pre-given world; a rational-ego may say it is part of interlocking web, but doing so collapses interior depth (subjective sphere) to the empirical dimension. Similarly systems theory (interobjective), albeit nonreductionist, suffers from subtle reductionism: a span-oriented collapse of interiority (yáng) to exteriority (yin). In absence of Selfhood, the Light of Plato's Cave is confused for the sum of the shadows (Wilber, 200o). Therefore, we are without a Westernised context for wisdom and growth in consciousness (NATURE) in objectivist and scientistic lenses. 
Concerning 'transformative' education, a theoretical impasse between self-responsible agency (critical pedagogy theorists) and self-abnegating communion (ecological pedagogy theorists) subsists-precisely because neither are transformational. Instead, agency and communion are horizontal and restrictive, thereby translational movements; "in ecological sensitivity 'is about lateral or outward relationships as opposed to forward or upward grasping [emphases added]' (Davis, 2004, p. 160). While eighty to ninety percent of experiential growth is translational, what masks (and hinders) vertical transformation ('passage beyond form') is that

self-adaptation and self-transcendence [are referred to] interchangeably [emphasis added], because both embody a type of 'going beyond'. But apart from that similarity, the two are different in degree and in kind. In self-adaptation or communion, one finds oneself to be part of a larger whole; in selftransformation one becomes a new whole, which has its own new forms of agency (relative autonomy) and communion. (Wilber, 2000, p. 5o)

According to Wilber (2000), most web-of-life theorists wish to 'equate a finite and temporal nature with an infinite and eternal Spirit [emphases added]' (p. 294). The idea of translative learning systems as open, adaptive, and enactive, is insufficient without the transformative (angelic) dimension within: 'it would be absurd to say that man, as man and by human means, can surpass himself' (Guénon, 1927/2004, p. 206). Therefore, we can classify the metaphysical context for sati of the East as oriented toward the subtle or yáng and the mindfulness of the West as oriented toward the gross or yin (Figure 2).

\section{On Metaphysics and the Possibility of Integration}

Historically, the modern calamity was reducing 'all introspective and interpretive knowledge to exterior and empirical flatland: [erasing] the richness of interpretation from the script of the world' (Wilber, 2000, p. I62); epistemic truth became independent from who presents it and to whom; 'for Descartes and his successors, timely questions were no concern of philosophy: instead, their aim was to bring to light permanent structures underlying all the changeable phenomena of Nature [emphasis added]' (Toulmin, 1990, p. 34). The drive to bring immutable structures (read: absolutes) into mutable conditions (read: naturalism) suffers from a misplaced metaphysical heritage of late Scholasticism. In short, we consider absolutism-in-naturalismleading to uniformity, permanence, and so on-as too yáng-in-yīn (pseudo-metaphysics), rather than too yáng in the context of metaphysics (Figure 3).

Postmodernists, on the other hand, 'would go to extraordinary lengths to deny depth [hierarchy] in general' (Wilber, 2000, p. 169). Without hierarchy—and greater discernment-all perspectives became equally valid. From a metaphysical perspective, anti-spiritual tendencies led to the solidification of the being and to 
conceptions of uniformity, atomism, and individualism (Guénon, 1945/2004); what followed was subsequent self-dissolution, rather than self-transcendence: a solid, atomistic shell led to a hollow one. Worse, since span was the only metric (bigger is better), ecological and complexity educational discourses (must) situate mind in the body (Figure 2);' thus we are part of what Davis (2004) calls a 'more-than-human' (whole) Earth. The contradiction that aims to regain a (qualitative) humanistic world while simultaneously placing humans within a horizontal, biocentric web-of-life is a severe conceptual error based upon a depthless view of the cosmos. As a result, with mindbody differentiation as the 'great mistake' (read: disenchantment), union with pre-conventional Nature via empirical-sensory awareness (environmental instinct, ${ }^{13}$ 直觉) caricatured a mind body integration (union) of post-conventional Spirit (intellectual intuition, 智的直覺). Eco-Romantically, the perspective of Earth as 'more-than-human' is alluring simply because the spatial metric is (perceived to be) more encompassing. But Eco-Noetically (traditionally), the Earth is less-than-human based upon the higher perspective of span and depth (Figure 2). Since unity was theorised in the Each and the All (systems approach) and not the One, a false spirituality (metaphysics) was developed, one ecological as opposed to intellectual.

As Wilber (2000) apprises, a qualitative distinction exists between differentiation and eventual integration (good), and dissociation (bad). In the Westernised context, linking mind with body through mindfulness may reverse dissociation ( $y \bar{m} n$ tendency), but integration is accomplished in view of the trans-rational ( $y a$ ang tendency). While modern science simply extracts and abstracts meditative practices such as mindfulness, in the Eastern context, mindfulness 'is the beginning of virtually all paths of contemplation, the aim of which is the remembering that one's true nature is Buddha-nature' (p. 339). Thus, sati resembles the Platonic reminiscence: 'that which is simply "learned" from the outside is quite valueless in the former case, however great may be the quantity of the notions accumulated; ... what counts is, on the contrary, an "awakening" of the latent possibilities that the being carries in itself' (Guénon, 1945/2004, p. 59). Thus, what accompanied traditional-as opposed to modern - theōria (contemplatio) was a corresponding 'realisation.'

Metaphysical discernment is limited in the West, ${ }^{14}$ primarily displaced by philosophical and religious treatises. The confusion between the study of ephemeral nature (physis) and the study beyond (sensory) nature (metaphysis from $\mu \varepsilon \tau \alpha$, 'beyond') is based upon a particular ignorance ${ }^{\mathrm{Is}}$ (avidy $\bar{a}$ )—one allegorised by Plato's Cave-rather than an inaccuracy of the modern and postmodern 'spirit' (or lack thereof). In the traditional, pre-modern West, a 'nature' that lay beyond playfulness (lilā) took on a sacred (sacratum) character, which is connected by no mere coincidence to secret (secretum) and mystery (musterion) which both designate silence and the inexpressible. As Guénon (1946/2004) expounded, sacratum and secretum both derive from the Latin secernere ('to place apart, put aside') which discerns (discere, 'to learn') the sacred from the profane. A deeper interpretation of musterion 'designates what must be received in silence' (p. I22) as seen in monastic and mystical orders. Spatially, 'a consecrated place is called templum, of which the root tem (found in the Greek temno, 'to cut,' 'to cut off from,' 'to separate,' from which temenos, 'a sacred enclosure,' is derived)' (p. I22). 
Contemplation, deriving from the root tem, strictly denotes an inwardness (depth), on the order beyond space and time, that is, toward the timeless and eternal.
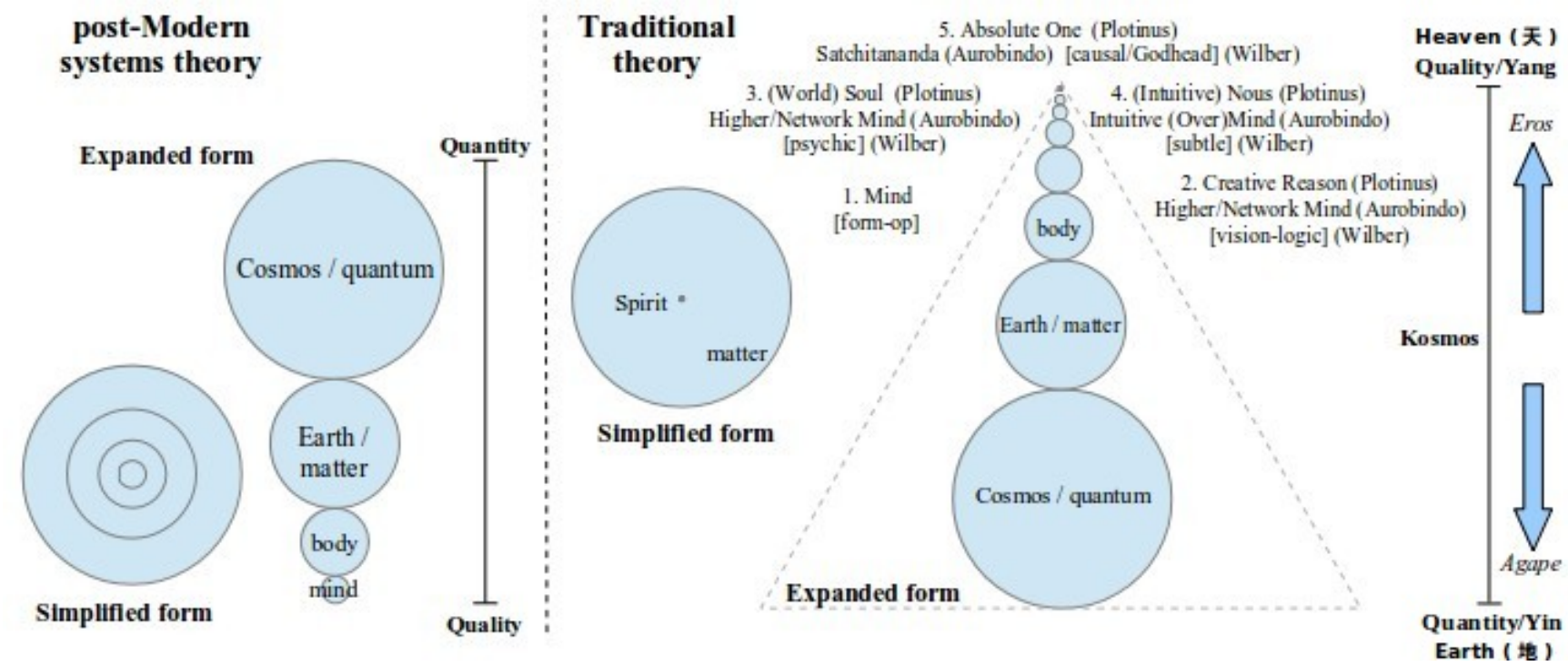

Figure 2: The cosmos vs. the (Pythagorean) Kosmos

Notes: Each circle represents a successive (bolonic) stage of consciousness or fulcrum (self-sense) for development. Conceptually, no capability of Eros or Ascent (transformation) exists in a Westernised (left) perception as Earth 'transcends' us as a 'more-than-human' and emergent phenomena. However, as we expand perception from \{span\} to \{span, depth\}, we correlate with traditional symbolism by placing humans between Heaven and Earth. The centre dot representing Spirit is subject to inverted spatial symbolism as it lies beyond space and time. Of note is the simplified form of systems theory which exemplifies our ecological too yáng-in-yīn critique (mind-in-body; more-than-human Earth; and so on) symbolised in Figure 3.

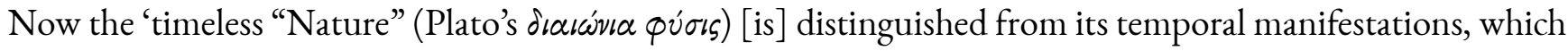
is the distinction of the stasis of that which is from the motion-and-rest of things that become' (Coomaraswamy, 1987, p. 65). Stasis (non-acting) cannot be rest (non-moving) as the latter depends upon spatiality. Manifestation at rest is truly frozen in an unstable equilibrium (too yáng-in-yin). The general pattern we see is that those grown up upon a false eternal framework of uniformity and universals, blame Plato (or modernity), and abandon metaphysics despite having never followed his educational thesis! Consider what Plato himself wrote in the Seventh Epistle:

I can affirm about any present or future writers who pretend to knowledge of the matters with which I concern myself [mystical knowledge of the One]; in my judgment it is impossible that they should have any understanding of the subject. It is not something that can be put into words like other 
branches of learning; only after long partnership in a common life [contemplative community] devoted to this very thing does truth flash upon the soul, like a flame kindled by a leaping spark. No treatise by me concerning it exists or ever will exist [emphasis added]. (as cited in Wilber, 2000, p. 329)

In other words, the Dao that one speaks of is not the true Dao as 'those who know don't talk; those who talk don't know' (Dào Dé Jing, 56, Red Pine translation). Truth is incommunicable and mystery inexpressible in the truest and most profound sense of the word. Certainty of objective truth is relative to certainty found in the union of our innermost Being (Schuon, 1970/2009). While the information age attempts to disentangle secrets and make everything 'known'-it must humbly accept one secret-and it just so bappens to be the very goal of Plato's educational journey toward wisdom.

A key characteristic in traditional science (metaphysics) is the emphasis placed upon qualitative hierarchy (scala nature), consciousness, and depth toward which mindfulness practices are directed. While natural science acknowledges quantitative hierarchy (mineral, plant, animal), metaphysicians placed relative import to the lower, quantitative domain due to its correspondence to the higher. ${ }^{16}$ To Guénon (1945/2004), modern science 'only takes account of the lower [domains], and being incapable of passing beyond the domain to which it is related, claims to reduce all reality to it' (p. 5). Such subtle reductionism toward an 'exclusively quantitative character [has] now become assimilated to that of purely mathematical theories [which] takes them yet further away from the sensible reality that they claim to explain, [one] situated on a lower plane than that of sensible reality' (p. I66). Now, the solution to uniformity or sameness on the surface (too yáng-in$y \bar{m}$ ) and diversity and the loss of sameness within (too $y \bar{m} n$ ) is the bolonic unit since uniformity (as pure quantity) is only a caricature of unity (as pure quality) whose true(r) reflection resides in the unit (Guénon, 1946/2004). As a disqualified unit spread homogeneously thin, uniformity takes on instrumental value as seen in agriculture, education, and so on. Similarly, the immobility (of rocks) is a caricature of the immutability of Spirit; while timely questions concern the temporal order, timelessness concerns the non-manifest order.

We can relate the traditional relationship between quality and quantity to Daoist symbolism, where manifestation occurs between two poles hierarchically arranged as Earth ( $D i$, 地) supporting manifestation below $^{17}$ and Heaven (Tiān, 天) covering manifestation above ${ }^{18}$ (see Figure 2). Heaven (pure Yáng) and Earth (pure $Y_{\bar{\imath}}$ ) are the primordial duality ${ }^{19}$ of manifestation, representing the active (masculine) and passive (feminine) principles respectively. ${ }^{20}$ Prior to their macro-cosmic differentiation is Taijii ('pinnacle,'太极) known in Western Scholasticism as Being, Essence, or the realm of possibilities of manifestation. Being lies beyond manifestation, unaffected by its manifest qualities and thus exemplifies a property of immutability. The realm of possibilities of non-manifestation is comprised in Non-Being or Wúji ('without pinnacle,'无 极), the principle of Being. Finally, the principle connecting these within Universal Possibility is the Dào (道). For this reason, non-Duality is greater than Unity. When we add Rén ('human,'人) and place it between Di and 
Tiān, we get the ternary Tiān-Di-Rén (天地人) depicting Rén as the Son or Daughter of Heaven and Earth. While Tàiji combines Heaven and Earth qua principle, Rén as a reflection of Täiji combines Heaven and Earth qua resultant. But if we consider the ternary Tiän-Rén-Di (天人地) the role of Rén now becomes the mediator or bridge between these poles (Guénon, 1946/199I) with manifold applications in Daoist training. ${ }^{21}$ Ergo, we are not part of Earth, but Earth is part of us (Figure 2), and we are part of the higher bypostasis of Spirit. However, without depth, and under quantitative and empirical zeal, we become much more terrestrial Sons and Daughters of Earth (too yin). However, it is these celestial spheres ( yáng tendency) where 'non-human' wisdom originates and mindbody integration occurs. Similarly, on the basis of intellectual intuition (suprarationality), metaphysicians would offer their own critique against rationality while simultaneously contextualising the Eco camp as subrational (e-motive).

\section{Contextualising Reason and the Possibility of Transcendence}

Our present understanding of metaphysics has either been marred by —and mistaken for-Cartesian mechanism (pseudo-metaphysics) or confused with metaphysical realism (modern science), neither which are universal, but rather representational, natural, and positive. Confusing the Cartesian-Newtonian (mechanical) notion, Davis (2004) exemplifies the postmodern perspective: 'the study of metaphysics, for Aristotle, had to do with the identification of unchanging laws and principles that govern forms and phenomena that exist in the realm of the physical [emphasis added]' (p. i6). Davis elaborated that 'since Aristotle's time, metaphysics has been taken up and applied in ways that depart from the original meaning' ( $p$. I6). We can hardly miss pointing out his role in doing so! ${ }^{22}$ And while Aristotle placed greater emphasis on reason, it was as the human reflection of the Logos-as evident from the etymology of logic - and not modern logic generally attributed to Aristotle today as a form of rationalism 'evolved' or 'refined' therefrom (Schuon, 1970/2009). In believing that the culmination of Aristotelian logic leads to modern logic as, at last, 'mature and efficacious ... they [the evolutionary rationalists] obviously are unaware that this flowering of a discipline of thought, while having its merits, goes more or less hand in hand with a weakening, or even an atrophy, of intellectual intuition [emphasis added]' (p.7)! Rectifying matters, Guénon (1924/2004) would unequivocally state:

Descartes limited intelligence to reason, that he granted to what he thought might be called 'metaphysics' the mere function of serving as a basis for physics, and that this physics itself was by its very nature destined, in his eyes, to pave the way for the applied sciences, mechanical, medicinal, and moral-the final limit of human knowledge as he conceived it. (pp. II, I2)

The other error in Cartesian mechanism was the mind-body dualism it implied; yet such dualism is levelled against Plato-despite being a nondualist — through an unfortunate (mis)interpretation of his Meno. ${ }^{23}$ For 
instance, we read: 'Plato's assertion that this world is an imperfect shadow of a nonsensorial ideal realm would seem to be implicated in the conceptual separation of mind and body' (Davis, 2004, p. I49). Ironically, Plato considered reason opinion, and distinction was made between pure Intellect (buddhi) - aliquid increatum et increabile — and its impure instrument (manas); buddhi (nous, vovs) - the order of intellectual intuitionarises when manas 'is brought to rest in its own source (cittam svayonāv upas 'ámyate) by a surcease from fluctuation' (Coomaraswamy, 1987, p. 21I) so that gnosis is reached through dementation (amanibhāva) when 'there is no longer a distinction of Knower from Known or of Knowledge and Being, but only a Knowledge as Being and a Being as Knowledge' (p. 212). Therefore, a necessity for Plato was to move beyond the discursiveness of reason-as mediate knowledge - to what is grasped immediately in divinis.

Now the postulates of rationalism are essentially defined, by all its forms, whether philosophical rationalism or otherwise, as 'a belief in the supremacy of reason, proclaimed as a veritable "dogma", and implying the denial of everything that is of a supra-individual order, notably of pure intellectual intuition [and] the exclusion of all true metaphysical knowledge [emphases added]' (Guénon, 1945/2004, p. 90). Therefore,

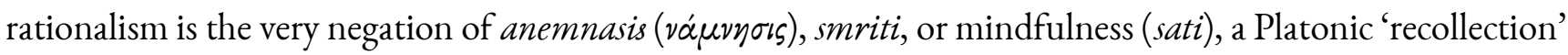
toward wisdom and our Buddha-nature. Providing incredibly insight as to why reason succumbs to antihierarchical tendencies - and thus evades transcendence-Wilber (2000) stated the majority of people

use reason without really knowing the ontogenetic stages that produced it. [It] is simply not immediately obvious to reason that reason itself developed or evolved. [Thus,] the natural stance of reason is to simply assume that it is apart from the world and can innocently reflect on it. (p. 45o)

Now the reflection paradigm is a legitimate (fifth) stage of consciousness (fulcrum or self-sense) where the rational-ego (as personal awareness) comprises the language of representation and reflection; unfortunately, as we have already noted, it is a monological representation and depth-less reflection concerning a pre-given world and pre-given subject (Wilber, 200o). Equally important is understanding the difference between what Jean Gebser called the mental consciousness crystallising around the time of Plato, Buddha, Laozi, and so on, and its deficient, rational mode. Far from a pinnacle of evolution:

the rational consciousness is the matrix of scientific materialism, virulent ethnocentrism, terrorism, and existential neuroses. It is a deficient form of consciousness, giving birth to deficient social and cultural manifestations. Far from being the summit of human accomplishment, the rational consciousness is an evolutionary cul-de-sac. (Feuerstein, 1992, p. 9)

Similarly, to Shiva (1989) - who argued that modern development is maldevelopment — stated that 'activity, ${ }^{24}$ productivity, creativity which were associated with the feminine principle are expropriated as qualities of 
nature and women, and transformed into the exclusive qualities of man. Nature and woman are turned into passive object'2s (p. 6). While we cannot ascertain the perspective of Shiva, we agree with her wording; we do not see the world as too masculine (yáng) which is expected from critical, ecological, or feminist angles; rather, the subtlety is that the male-oriented view has usurped the feminine principle (Figure 3).

\section{Remarks on Contemplation, Rationality, and Mindfulness}

The present antithesis between East and modern West consists (and subsists) 'in the fact that the East upholds the superiority of contemplation over action, whereas the modern West on the contrary maintains the superiority of action over contemplation' (Guénon, 1927/2004, p. 36). Plato would distinguish reason (ratio)

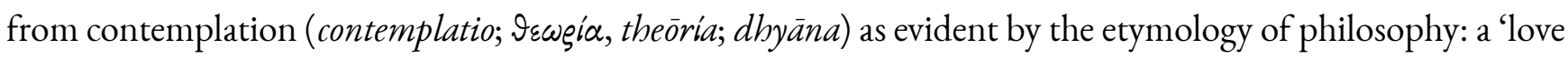
of wisdom' cannot be wisdom, but points to a higher, 'non-human' source. Another fundamental difference between East (or traditional West) and modern West is that the former-with the possibility of interior development-attempts to become a higher vestige of one-Self whereas the latter attempts to disprove the highest thinker of one's era. In over 2000 years no one has disproved the Buddha; instead, all sincere aspirants try and reach their Buddha-nature. In the Westernised context, one (often) succumbs to a battle for superiority, a mental jousting of one's own ideologies and prestige; as a result, blatant polemical attacks thoroughly infuse postmodern criticism, slighting the fact that without diverse views there can be no conceptual (or dialogical) growth! Given the spiritual degeneration, however, perennialist Schuon (200I/2007) would speak frankly:

All civilizations are fallen, but in different ways: the fall of the East is passive; the fall of the West is active. The fault of the fallen East is that it no longer thinks; that of the fallen West is that it thinks too much, and wrongly. The East is sleeping over truths; the West is living in errors. (pp. I7, I8)

In our concern for education, we must address the fundamental duality of contemplation and action as it relates to liberation (mokșa) or transformation of the student. Contemplation, zen, or non-action (wú wéi, 无 为) corresponds to the heavenly pole and action (karma) corresponds to the earthly pole. Staying true to metaphysics, contemplation finds manifestation in action as change finds its superior principle in the unchanging. Moreover, action, 'being merely a transitory and momentary modification of the being, cannot possibly carry its principle and sufficient reason in itself; if it does not depend on a principle outside its own contingent domain, it is but illusion [emphasis added]' (Guénon, 1927/2004, p. 37). So 'action, no matter of what sort, cannot under any circumstances liberate from action; in other words, it can only bear fruit within its own domain, which is that of human individuality [emphasis added]' (Guénon, 1925/2004, p. I58), or the domain of possibility for agency and communion. So the very possibility of action is found in 'contemplation, or, if one will, in [metaphysical] knowledge, for these two terms are fundamentally synonymous, or at least 
coincide, since it is impossible in any way to separate knowledge from the process by which it is acquired' (Guénon, 1927/2004, p. 37). Therefore, metaphysicians are astounded that movement and change (exclusively yin) are actually 'prized for their own sake, and not in view of any end to which they may lead [Being]; this is a direct result of the absorption of all human faculties in outward action whose necessarily fleeting character [implies] dispersion' (1927/2004, p. 38). Herein lies the context for pragmatism, whose action-oriented philosophy sparked both social and educational reform.

Pragmatism has historically substituted truth for utility — coinciding with predictive power (Wilber, 200o) and the foundational branches of science (and education) essentially became a science of rocks (the least in holonic consciousness); "the "ideal" of [scientific] knowledge as predictive power would ruin virtually every field it was applied to (including rocks) because its very methods would erase any creativity it would find, thus erasing precisely what was novel, significant, valuable, meaningful' (Wilber, 2000, p. 56). While pragmatists are certainly apprehensive of industry and its application in education-arguing for experiential learning against uniformity, standardisation, and a pre-given world-we cannot help but notice both pragmatism and mechanism derive from the same premise of a superiority of action; in seeking to overcome the deficiencies of a "mechanistic" education, has pragmatism inevitably strengthened the very premise of uniformity in curricular standardisation?

\section{Respecting the Yáng}

In a traditional (read: spiritual) approach to education, the disciple aimed to transcend the limitation ${ }^{26}$ of their lower mind ( $x \bar{i} n$, 心) and general psychosomatic constitution. Unfortunately, a historical precedent was set to abandon the mind and neglect the body in antimaterial spirituality-what we consider legitimately as too yáng. In Zen or Chán (禅) Buddhism, one 'stunk of Zen' if unbalanced toward shén (神). Nonetheless, each stabilised fulcrum beyond reason is a trans-rational contemplative development that may be rationally explained or reconstructed, but never rationally experienced. In transpersonal psychology, the higher fulcrums of awareness are categorised as vision-logic (centaur), psychic, subtle, causal, and nondual (Wilber, 200I). Vision-logic is an integral-aperspectival mind, adding 'up all the perspectives tout ensemble, and therefore privileges no perspective as final: it is aperspectival' (Wilber, 2000, p. 193). The bodymind holon of the centaur is an intersubjective transcendence from universal perspectivism (rational holon), capable of integrating body and mind: a mind looking at the mind intersubjectively as opposed to operating within the mind alone (reflection paradigm). For Gebser, the vision-logic consciousness that surpassed the mental was his integral consciousness,

associated with ego-transcendence (rather than egolessness), self-transparency, freedom from anxiety (especially from the fear of time), openness, emotional availability and fluency, participatory freedom, 
personal responsiveness, bodily presence (rather than abstraction from life), the ability for genuine intimacy, equanimity, reverence for all life, the capacity for service, and love. (Feuerstein, 1992, p. 19)

Each interior stage of consciousness has an exterior correlate (Figure 2). ${ }^{27}$ According to Wilber (200I), a centaur uses hermeneutic (interior) depth (dialectical and dialogical) and (exterior) developmental (evolution and network) languages. The psychic begets inner vision and exterior vibration (of intensity, not physics). The subtle domain exemplifies the saint comprising inner luminosity and outer Platonic archetypes. The causallevel exemplifies the sage who recognises the emptiness behind the great dream $(m \bar{a} y \bar{a})$ and dancing play $(l \bar{l} l \bar{a})$ of manifestation. And the language of the nondual is the extraordinary ordinary, where interior and exterior are One in the siddha.
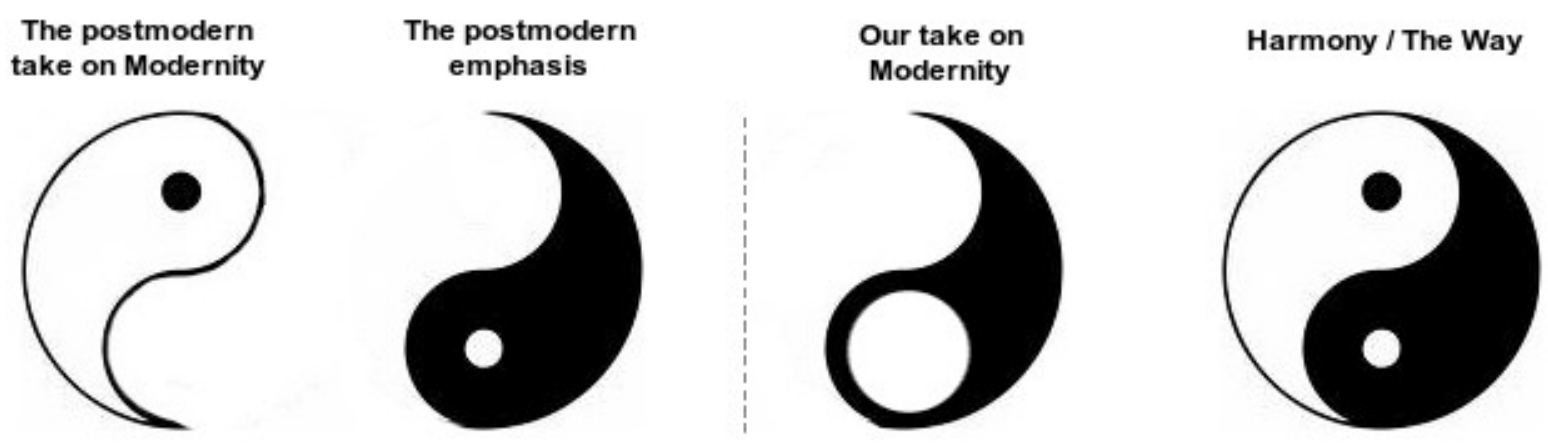

Figure 3: Differences in unbalanced worldviews on modernity through the perspective of Daoist imagery

Notes: The postmodernist view en-visions modernity as too yáng whereas we see it as too yáng-in-yin based on the subtle nature of the collapse of the yáng to the yin (Figure I); thus, the yáng was left to assume the position of the yin. In this conceptual map, we contextualise both Figures I and 2 and the subtle reductionism inherent in translative movements mistaken for authentic spiritual transformation. The lack of discernment between uniformity and unity, as well as a 'more-than-human' biosphere is also encompassed in our take on modernity. If the absurdity of the symbol is in question, so too, we argue, is the lack of discernment in the aforementioned paradoxes that result from a lack of depth and genuine contemplation.

Now the triumphant return of the (balanced) feminine principle — at least academically — has been to the detriment and omission of its yáng or masculine counterpart. Naturally, one cannot conceive of a purely yìn universe and concede yáng entirely, nor a dichotomy of yin and yáng; however, in a theologically or metaphysical context, we have left Heaven ( yáng) for Earth (yin). Should we tend solely toward the needs inherent in the material side of our nature, the aim becomes 'quite illusory since it constantly creates more artificial needs than it can satisfy [emphases added]' (Guénon, 1927/2004, p. I7). Therefore, despite 
theoretically removing the yáng-in-yin imbalance from modernity—to which we applaud-we are left spirituality impoverished with the integrative absence of involution (yáng tendency).

\section{Concluding Remarks}

To summarise mindfulness - the foundation of contemplation—we present the phrase 意念 ( yi nián) or 'wisdom mind-thought.' The Chinese character niàn 念 is comprised of jin (今) 'now; this' and xin (心) 'heart; mind' which captures the moment-to-moment awareness which manifests a state of here-and-now oneness through embodied engagement ( $\mathrm{Lu}, 2 \mathrm{OI2})$. Together, 意念 relates the wisdom mindfulness is oriented toward. And according to Wallace (2006), contextualising mindfulness practice toward mental balance (samādhi) includes attention (śamatha), contemplative insight (vipaśyanā), and the cultivation of the four immeasurables: loving-kindness (metta), compassion (karuñā), empathetic joy (muditā), and equanimity (upekșa). In the Indo-Tibetan context, one does not refrain 'from labelling or categorising experiences in a nonjudgmental fashion; ${ }^{28}$ [instead] in the earliest, most authoritative accounts, sati is said to distinguish between wholesome and unwholesome, beneficial and unbeneficial tendencies. The contrast between the ancient and modern accounts is striking' (p. 6I).

Having presented the foundations for the traditional practice(s) of mindfulness, we hope our contextual efforts and conceptual map (Figure 3 ) aid pedagogical theorists toward qualifying a mindful education embracing Eastern wisdom. Further education research may elucidate mindfulness toward the integralaperspectival mind, so long as the yáng (spiritual) element is in continual balance with the yinn, and vice versa.

\section{Disclosure statement}

No potential conflict of interest was reported by the authors. 


\section{End Notes}

I. In a Qigong context, we note Yang's (1997) use of the word yi (意) meaning the mind related to clear thinking, judgment, and wisdom.

2. Following Wilber (2000), we leave Nature (environment) capitalised to distinguish between human nature and metaphysical NATURE (Figure I).

3. To Shiva (1989), subject-less knowledge creates a dichotomy; the 'fact-value dichotomy is a creation of modern reductionist science, while being an epistemic response to a particular set of values, posits itself as independent of values [emphasis added]' (pp. 26, 27): a paradox of relativism.

4. A Latin, theological phrase meaning 'in the aspect of eternity.'

5. c.f. On metaphysics and the possibility of integration; we denote what is fixed (as permanence) as too yáng-in-yin and its metaphysical counterpart, stasis, as yáng. See also Appendix A.

6. A term in contrast to dialogical and trans-logical. Monological investigation implies theorising on what we observe through our senses and subsequent extensions.

7. An analysis of the manifold application of the tool vs. the machine is beyond the scope of our paper. However, we wish to expound that uniformity is in no way too yáng in contrast to diversity or yin; rather, it results from a worldview with too yáng-in-yin (Figure 3).

8. More qualifiers exist, but disciple in particular is of two forms: outward, often associated with a religious West, and inward, often associated with a meditative East.

9. This would imply that science taught in education is unreliable at worst, and generally over-simplified at best; and any systemisation leads to exclusion: a topic beyond the scope of our paper.

Io. The Daoist scholar would have little issue with this paradox as yin is within yáng and yáng within yin.

II. It is prudent to note that horizontally, agency relates to the masculine ( yáng) and communion relates to the feminine $(y \bar{m})$. However, in the vertical context (Figure 2), these earthly yin and yáng movements are yin in relation to the vertical yáng archetype of Spirit or shén.

I2. An inversion where yáng is now situated in yīn, hence too yáng-in-yīn.

13. Also known as vitalistic intuition.

I4. The exception being esoteric currents of pre-Pauline Christianity.

I5. In Buddhist China. avidy $\bar{a}$ (无知, ignorance, suffering; Tibetan: ma rigpa) is the first of twelve chains or causes (nidānas) applicable to pratityasamutpāda ('dependent origination' or 'interdependent coarising') and connects with suffering (dubkba) or unsatisfactoriness (Tibetan: sdug bsngal).

16. The 'double truth' in Buddhism: one relative and conventional, the other absolute and certain (Coomaraswamy, 1947).

17. Or substance in Scholastic terminology, from sub-stare, 'that which stands beneath.'

I8. Or essence in Scholastic terminology.

19. Rather than 'dualism' which is necessarily a 'naturalism' if conceived as being irreducible. 
20. Unfortunately, such symbolism has historically manifested as patriarchal systems. We are certainly not against these many critical, feminist, and deep ecological criticisms. We simply allude to the fact that these two tendencies are found within all manifested reality to such and such a degree.

2I. Like mindfulness, Qigong as a hierarchical practice is extracted and abstracted from the sequence Wàigōng 外功 (External Work), Nèigōng 内功 (Internal Work), Qìgōng 气功 (Energy Work), and Shéngōng 神功 (Spirit Work).

22. To his credit, Davis himself is a strong advocate for the bermeneutic circle where one places their intersubjectivity at face value to contextualise and transcend. Without his formulations on educational complexity and deep ecology, we would not have had the opportunity to write and present our own thesis.

23. While we cannot address the intricacies of Meno, we assume the spiritual process Plato described was exosomatosis.

24. If we remain strictly with Daoist teachings, we note that the masculine principle is active and the feminine principle passive. Here activity as a noun should be replaced with action which has its proper correlation with contemplation which is truly active. A better descriptor would be movement.

25. In a similar vein, the subjugated subjects (biopower) of Michel Foucault and debumanising humanism of Jürgen Habermas concerned a collapse of dialogical subjects into monological objects: a psendoscience based on 'self-aggrandizing power' (Wilber, 2000, p. 464).

26. If the mental faculty was not limited, what need would anyone have in transcending it? 27. This is why mindfulness can be measured as brain waves.

28. As seen in Western mindfulness deriving from Western psychology.

\section{References}

Bowers, C. (2010). Toward an eco-justice pedagogy. Environmental Education Research, 8, 2I-34.

Blom, R., Lu, C., \& Mgombelo, J. (2015). Mindful pedagogy: Invocating the concept of play beyond the confines of recess. Paideusis: Journal of the Canadian Philosophy of Education, 22, 38-49.

Capra, F. (1997). The web of life: A new scientific understanding of living systems. New York, NY: Anchor. Coomaraswamy, A. K. (1947). Time and eternity. Ascona: Artibus Asiae.

Coomaraswamy, A. K. (1987). Metaphysics. Princeton, NJ: Princeton University Press.

Davis, B. (2004). Inventions of teaching: A genealogy. Mahwah, NJ: Lawrence Erlbaum.

Feuerstein, G. (1992). Wholeness or transcendence? Ancient lessons for the emerging global civilization. Burdett, NY: Larson Publications.

Guénon, R. (1924/2004). East and west. (M. Lings, Trans.). Hillsdale, NY: Sophia Perennis. 
Guénon, R. (1925/2004). Man and bis becoming according to the Vedānta (R. Nicholson, Trans.). Hillsdale, NY: Sophia Perennis.

Guénon, R. (1927/2004). The crisis of the modern world (R. C. Nicholson, A. Osborne, \& M. Pallis, Trans.). Hillsdale, NY: Sophia Perennis.

Guénon, R. (1945/2004). The reign of quantity and the signs of the times (L. Northbourne, Trans.). Hillsdale, NY: Sophia Perennis.

Guénon, R. (1946/199I). The great triad (P. Kingsley, Trans.). Ghent, NY: Sophia Perennis.

Guénon, R. (1946/2004). Perspectives on initiation (H. D. Fohr, Trans.). Ghent, NY: Sophia Perennis.

Lodewyk, K., Lu, C., \& Kentel, J. (2009). Enacting the spiritual dimension in physical education. The Physical Educator, 66, 170-179.

Lu, C. (2012). Integrating mindfulness into school physical activity programming. Teaching and Learning, 7, $37-46$.

Schuon, F. (1970/2009). Logic and transcendence: A new translation with selected letters (M. Perry, J. Lafouge, \& J. S. Cutsinger, Trans.). Bloomington, IN: World Wisdom.

Schuon, F. (200I/2007). Spiritual perspectives and buman facts (M. Perry, J. Lafouge, \& J. S. Custinger, Trans.). Bloomington, IN: World Wisdom.

Shiva, V. (1989). Staying alive: Women, ecology and development. London: Zed Books.

Smith, D. G. (2006). Trying to teach in a season of great untruth. Rotterdam: Sense Publishers.

Toulmin, S. (1990). Cosmopolis: The hidden agenda of modernity. Chicago, IL: The University of Chicago Press.

Wallace, B. A. (2006). The attention revolution: Unlocking the power of the focused mind. Somerville, MA: Wisdom.

Wilber, K. (200o). Sex, ecology, spirituality: The spirit of evolution. Boston, MA: Shambhala.

Wilber, K. (200I). The eye of spirit: An integral vision for a world gone slightly mad (3rd ed.). Boston, MA: Shambhala.

Yang, J. (1997). The root of Chinese qigong: Secrets for health, longevity, ES enlightenment. Wolfeboro, NH: YMAA Publication Center. 


\section{Appendix A. Catalogue of terminology}

\begin{tabular}{|c|c|c|}
\hline Mindfulness (yìn-yáng) & Modern (too yáng-in-yin) & (W)holistic (too yin) \\
\hline Mindbody integration & Mindbody dissociation & Mindbody pre-differentiation \\
\hline Simple & Complicated & Complexity \\
\hline Holons & Parts & Wholes \\
\hline Qualitative superiority & Quantitative superiority & Balance between quantity and quality \\
\hline Trans-rational & Rational & Pre-rational and rational \\
\hline $\begin{array}{l}\text { Kosmic agency-in-communion } \\
\text { (enactivism) }\end{array}$ & Stunted agency (reason only) & Gaian participation (communion) \\
\hline Supra-human & Infra-human & Human \\
\hline Eco-noetic & Ego-enlightened & Eco-romantic \\
\hline Unity in multiplicity & Uniformity & Multiplicity \\
\hline NATURE & Nature & Nature and nature \\
\hline Spiritual & Mechanical & Ecological \\
\hline Metaphysics & Physics & Biology \\
\hline Integral & Empirical & Phenomenological \\
\hline Wisdom & Information & Lived experience \\
\hline Product of the process & Product & Process \\
\hline Depth (and span) & Span & Span \\
\hline Knowledge & Known & Knower \\
\hline Synthesis & Analytical & Systems \\
\hline Contemplative superiority & Active superiority & Active superiority (pragmatism) \\
\hline Centaur vision logic & Egoic rationality & Emotions \\
\hline
\end{tabular}

